\title{
Efficiency improvement of technical condition assessment of plunger pairs of diesel fuel equipment
}

\author{
Anatolii Eremeev*, Aleksandr Morozov, and Dmitry Kotkov \\ Federal State Budgetary Educational Institution of Higher Education Ulyanovsk State Agrarian \\ University, Ulyanovsk, Russian Federation
}

\begin{abstract}
Usage of an upgraded device for assessing technical condition of plunger pairs makes it possible to increase assessment accuracy and reduce the number of erroneously rejected plunger pairs. The action of this device is based on introduction of automatic hydraulic pressure test time record into the evaluation process.
\end{abstract}

\section{Introduction}

A large number of agricultural machinery in the agro-industrial complex is equipped with diesel power plants, the efficient and regular operation of which depends on reliable operation of diesel fuel equipment. It is necessary to check regularly the condition of the fuel equipment during its operation. Testing and adjustment of fuel equipment is the most important technological operation in repair and maintenance of diesel engines. In this view, the adjustment of fuel equipment during its technical maintenance and repair is of particular importance.

One of the most important adjustment parameters is uniform fuel distribution in sections [1]. Uneven fuel flow to the engine cylinders leads to engine unstable operation; interruptions in operation of individual cylinders at a low crankshaft speed, significant vibration of the engine block; load increase on the crank mechanism and the cylinder-piston group; decrease of engine power and reliability; higher fuel consumption. As the research shows $[2,3,4]$, uneven fuel delivery by fuel pump sections reduces engine power by $10 \ldots$ $15 \%$, which leads to a corresponding increase in fuel consumption. The uniformity of fuel flow directly depends on hydraulic density of fuel pump plunger pairs.

Disbalance of fuel distribution is caused by wear of plunger pairs, pressure control valves, fuel distribution control mechanism (plunger levers, rack clamps, rack teeth and bush ring gear), therefore, the issues of proper assessment of technical condition of the plunger pairs are currently important.

The analysis of the existing methods and devices for assessing the technical condition of plunger pairs $[5,6]$ showed that they do not fully meet the requirements for accuracy and productivity of assessment work. To eliminate these drawbacks, it is proposed to upgrade the existing device KI-759 for testing the hydraulic density of plunger pairs by installing a

${ }^{*}$ Corresponding author: erem.an@mail.ru 
device for automatic record of hydraulic pressure test time, which will help to increase the accuracy of plunger pairs distribution into groups, taking into account their hydraulic density.

\section{Methodology of Researches}

The upgraded KI-759 device consists of the plate 1 with the stand 2 (Figure 1), where the body frame is fixed 3 . The setting head projections 4 fit into the slots of the body frame. The setting head is fixed in the body frame by a pressure screw with a tap wrench 5 .

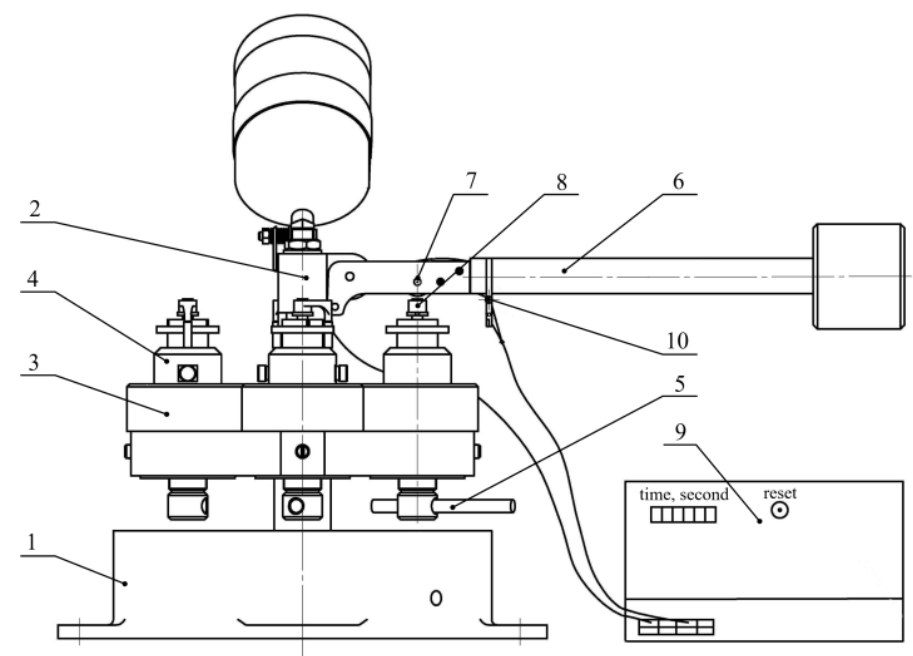

Fig. 1. Upgraded device KI-759 with a device for automatic record of hydraulic pressure test time of plunger pairs: 1 - a plate; 2 - a stand, 3 - a body frame; 4 - a setting head; 5 - a pressure screw with a tap wrench; 6 - a lever; 7 - a roller with a strain-measuring gauge; 8 - plunger shank, 9 - electronic stopwatch; 10 - infrared sensor.

A stand is pressed into the base of the device, to which a lever is attached 6 . The lever is designed to create a static load during hydraulic pressure testing on the plunger through a roller with a strain-measuring gauge 7 . The mass and size of the lever 6 are selected so that when it is lowered, the fuel under the plunger is compressed by constant pressure, which is 2.2 MPa for plunger pairs of pump type FP 1 . When the lever touches the plunger shank 8 an electronic stopwatch 9 is started by means of a strain strain-measuring gauge. Then, when the plunger moves down, a "fuel cut" occurs, the lever drops sharply, the signal from the infrared sensor 10 stops the electronic stopwatch 9. The time period when the plunger will slowly lower under the action of the lever mass will characterize the hydraulic density of the plunger pair.

The human factor exclusion from the assessment process of the technical condition of the plunger pair and time measurement of the hydraulic pressure test with an electronic stopwatch will make it possible to determine hydraulic density of the tested plunger pair more accurately. The application of this device enables to select the plunger pairs more efficiently in terms of hydraulic density, and, consequently, to increase the reliability, resource, power of engines and reduce fuel consumption during their operation.

When assessing the usage effectiveness of the upgraded device, the hydraulic density of the plunger pairs was first determined on a standard KI-759 device, then similar operations were performed with the same plunger pairs on the upgraded KI-759 device with automatic record of hydraulic pressure test time and the obtained data were analyzed. 
For this, the plunger pairs were visually inspected for damage and numbered. The fuel tank of the device was filled with process fluid. The plunger pair to be checked was installed in the setting head, the plunger bush was fixed in the setting head with a screw, the plunger was lifted by the shank to the extreme upper position, the tank valve was opened for supplying the process fluid, the plunger was installed in the bush. A hand stopwatch was used to measure the hydraulic pressure test time. Similarly, each plunger pair was tested three times.

After that, the hydraulic density of the same plunger pairs was checked on the upgraded KI-759 device with automatic record of hydraulic pressure test time (Figure 2.).

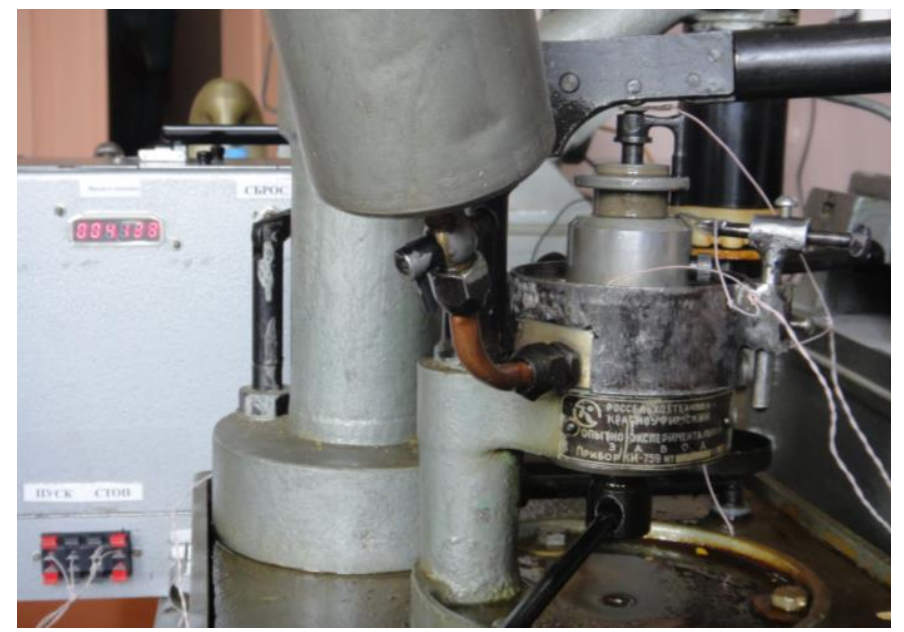

Fig. 2. Upgraded device KI-759 with automatic record of hydraulic pressure test time.

The instrument was pre-tuned using a reference plunger pair. The reference plunger pair was also checked three times, and the device was "zeroed" before the next check. The data obtained from the reference plunger pair were further used to distribute the plunger pairs by density groups. Then, the hydraulic density of the plunger pairs was re-checked on the upgraded KI-759 device with automatic record of hydraulic pressure test time.

\section{Research Results and Discussion}

The results of hydraulic density measurement of the plunger pairs under study on the reference device and the upgraded one were tabulated in Table 1.

Table 1. The main parametres of plunger pairs of fuel pumps UTN-5 when assessing their technical condition.

\begin{tabular}{|c|c|c|c|c|c|}
\hline \multicolumn{2}{|c|}{ Assessment of technical condition of plunger pairs on a standard device KI-759 } \\
\cline { 2 - 5 } & \multicolumn{2}{|c|}{ hydraulic pressure test time, $\mathrm{s.}$} & $\begin{array}{c}\text { mean } \\
\text { value }\end{array}$ & $\begin{array}{c}\text { Deviation from the } \\
\text { readings of the record } \\
\text { device }\end{array}$ \\
\cline { 2 - 5 } & 1 test & 2 test & 3 test & 5,3 & 2,283 rejection \\
\hline 1 & 5 & 5 & 20 & 21,3 & 9,025 \\
\hline 2 & 22 & 22 & 11 & 12 & 3,416 rejection \\
\hline 3 & 12 & 13 & 4,2 & 3,2 & rejection \\
\hline 4 & 3,4 & 2 & 8,2 & 7,87 & 1,476 rejection \\
\hline 5 & 8 & 7,4 & 20 & 14,3 & 1,984 \\
\hline 6 & 13 & 15 & 1,4 & 1,77 & rejection \\
\hline 7 & 2,1 & 1,8 & 10,4 & 11,13 & 2,407 rejection \\
\hline 8 & 10 & 13 & & & \\
\hline
\end{tabular}




\begin{tabular}{|c|c|c|c|c|c|}
\hline \multicolumn{7}{|c|}{ Assessment of technical condition of plunger pairs on upgraded device KI-759 with automatic } \\
record of hydraulic pressure test time \\
\hline \multirow{2}{*}{ plunger pair } & hydraulic pressure test time, $\mathbf{s .}$ & mean & Suggested density group \\
& 1 test & 2 test & 3 test & value & \\
\hline Reference pair & 50,348 & 50,370 & 50,354 & 50,354 & I \\
\hline 1 & 7,648 & 7,320 & 7,782 & 7,583 & III \\
\hline 2 & 30,231 & 30,734 & 30,012 & 30,325 & I \\
\hline 3 & 15,484 & 15,321 & 15,443 & 15,416 & II \\
\hline 4 & 5,378 & 5,979 & 5,010 & 5,455 & rejection \\
\hline 5 & 9,983 & 9,045 & 9,011 & 9,346 & III \\
\hline 6 & 16,327 & 16,493 & 16,032 & 16,284 & II \\
\hline 7 & 5,899 & 5,117 & 5,238 & 5,418 & rejection \\
\hline 8 & 13,289 & 13,367 & 13,956 & 13,537 & II \\
\hline
\end{tabular}

For a better assessment of the technical condition of the plunger pairs, it is proposed to distribute the hydraulic pressure time according to hydraulic density groups (Table 2).

Table 2. Distribution of plunger pairs by hydraulic density groups depending on the value of the hydraulic pressure test.

\begin{tabular}{|c|c|}
\hline \multicolumn{2}{|c|}{ Standard parametres } \\
\hline hydraulic pressure test time, $\mathrm{s}$. & Density group \\
\hline below 4.99 & rejection \\
\hline $5.00 \ldots .99$ & I \\
\hline $10.00 \ldots 14.99$ & II \\
\hline $15.00 \ldots 19.00$ & III \\
\hline $20.00 \ldots 24.99$ & IV \\
\hline $25.00 \ldots .29 .99$ & V \\
\hline
\end{tabular}

Based on the results of checking of the plunger pairs received for technical condition assessment, data were obtained (Table 2), on the basis of which the graphs of group distribution by the hydraulic density of the plunger pairs were built (Figure 3 - 4).

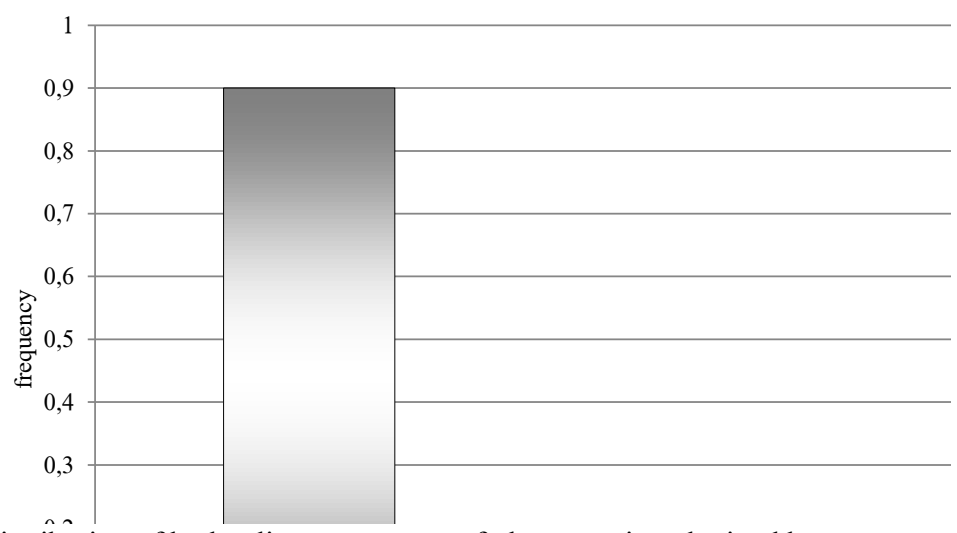

Fig. 3. Time distribution of hydraulic pressure test of plunger pairs, obtained by measurement on a standard KI-759 device. 


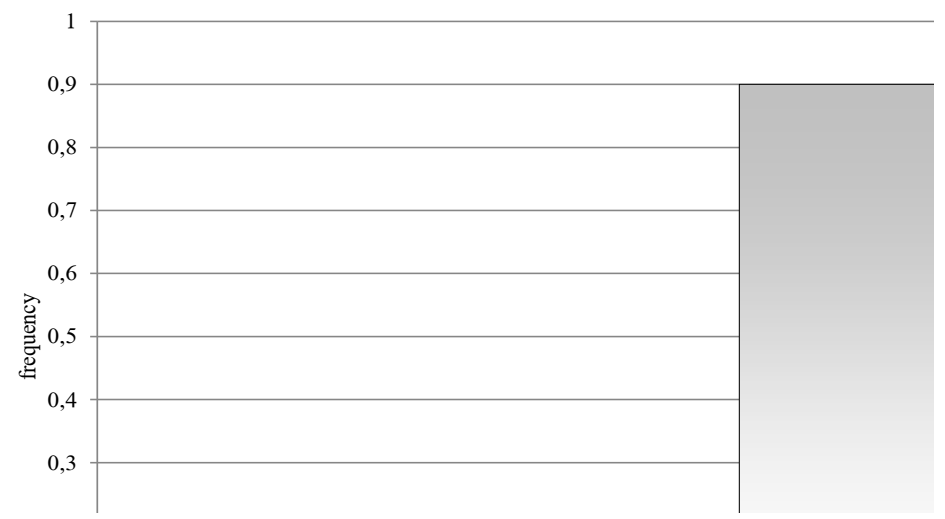

Fig. 4. Time distribution of hydraulic pressure test of plunger pairs, obtained by measurement on upgraded KI-759 device with automatic record of hydraulic pressure test time.

The analysis of the data obtained showed that when assessing the technical condition of the plunger pairs with the upgraded KI-759 device with automatic record of hydraulic pressure test time, four of the six plunger pairs rejected by the standard method can be used in further operation.

\section{Conclusion}

The analysis showed that the accuracy of diesel fuel equipment adjustment has a significant effect on the output parameters of diesel engines and their performance. For example, uneven fuel distribution by fuel pump sections reduces engine power by $10 \ldots 15 \%$, which leads to an increase in fuel consumption. It is revealed that the main characteristics of fuel equipment largely depend on technical condition of the plunger pairs of the fuel pump.

The existing methods for assessing the technical condition do not fully meet the requirements for accuracy and productivity of assessment work.

An upgraded device for technical condition assessment of plunger pairs is proposed, its operation is based on introduction of automatic record of hydraulic pressure test time into the assessment process.

Conducted comparative tests showed that in case of usage of the upgraded device with automatic record of hydraulic pressure test time to assess the technical condition of plunger pairs, up to $66 \%$ of the plunger pairs rejected by a standard device can be used in further operation on fuel pumps without refurbishment.

\section{References}

1. B.P. Zagorodskikh, V.P. Lyalyakin, P.A. Plotnikov, Repair and regulation of fuel equipment for automotive and combine diesels (Moscow, FGNU "Rosinformagrotech", 2006)

2. V.V. Varnakov, A.N. Eremeev, Operational methods for improving the performance of tractor diesels (Bulletin of the Ulyanovsk state agricultural Academy, v. 11, 2004)

3. V.V. Varnakov, A.N. Eremeev, D.V. Varnakov, Operational methods for improving the performance of diesel engines (Repair. Recovery. Modernization, v. 10, 2006)

4. A.E. Abramov, A.V. Morozov, A.O. Koshkina, S.N. Petryakov, Ju.V. Nuretdinova, The cleaning process model of diesel fuel in an electric field (Matec web of conferences, The proceedings international conference on modern trends in 
manufacturing technologies and equipment: Mechanical engineering and materials science, 2019)

5. A.N. Eremeev, K. R. Kundrotas, A.V. Khramkova, A.Yu. Kundrotene, Improving the efficiency of assessing the technical condition of plunger pairs, Bulletin of the Ulyanovsk state agricultural Academy, v. 4, 2012)

6. V.V. Varnakov, A.N. Eremeev, O.N. Filimonova, V.I. Zhiganov, M.E. Dezhatkin, D.V. Varnakov, V.I. Kurdyumov, Device for evaluating the technical condition of plunger pairs (Patent RU 2244152 C2, 2005) 